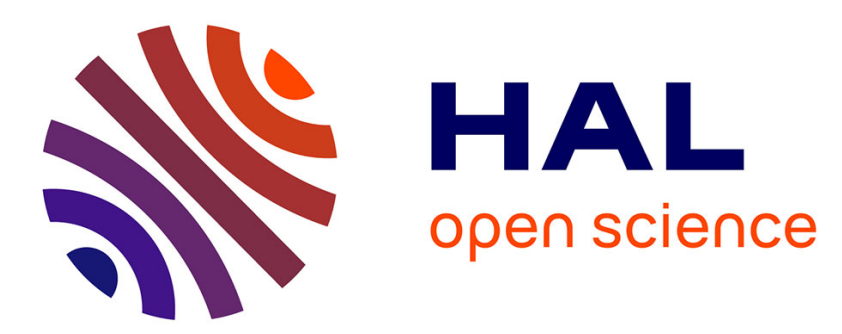

\title{
Cluster calculations of the electronic d-states in VO2
}

\author{
C. Sommers, R. de Groot, D. Kaplan, A. Zylbersztejn
}

\section{To cite this version:}

C. Sommers, R. de Groot, D. Kaplan, A. Zylbersztejn. Cluster calculations of the electronic d-states in VO2. Journal de Physique Lettres, 1975, 36 (5), pp.157-160. 10.1051/jphyslet:01975003605015700 . jpa-00231177

\section{HAL Id: jpa-00231177 https://hal.science/jpa-00231177}

Submitted on 1 Jan 1975

HAL is a multi-disciplinary open access archive for the deposit and dissemination of scientific research documents, whether they are published or not. The documents may come from teaching and research institutions in France or abroad, or from public or private research centers.
L'archive ouverte pluridisciplinaire HAL, est destinée au dépôt et à la diffusion de documents scientifiques de niveau recherche, publiés ou non, émanant des établissements d'enseignement et de recherche français ou étrangers, des laboratoires publics ou privés. 


\title{
CLUSTER CALCULATIONS OF THE ELECTRONIC d-STATES IN $\mathrm{VO}_{2}$
}

\author{
C. SOMMERS \\ Laboratoire de Physique des Solides, Université Paris XI, \\ 91405 Orsay, France \\ R. DE GROOT $\left(^{*}\right)$ \\ Centre de Calcul Atomique et Moléculaire, \\ 91401 Orsay, France \\ D. KAPLAN and A. ZYLBERSZTEJN \\ Laboratoire Central de Recherches, Thomson-C.S.F., \\ 91401 Orsay, France
}

(Reçu le 27 janvier 1975, accepté le 6 mars 1975)

\begin{abstract}
Résumé. - Un calcul des états électroniques $\mathrm{d}$ de $\mathrm{VO}_{2}$ à partir des premiers principes a été effectué. On utilise, de manière auto-cohérente, la méthode par diffusion multiple, avec traitement statistique de l'échange. Un octaèdre $\mathrm{VO}_{6}^{8-}$ a été utilisé pour représenter la phase tétragonale et un amas $\mathrm{V}_{2} \mathrm{O}_{10}^{12-}$ avec des atomes de vanadium appariés a été utilisé pour la phase monoclinique. Les résultats obtenus sont en contradiction avec une explication de l'origine de la bande interdite du semiconducteur en terme de séparation de bandes induite par la distorsion.
\end{abstract}

\begin{abstract}
An ab-initio cluster calculation of the electronic d-states in $\mathrm{VO}_{2}$ has been made by

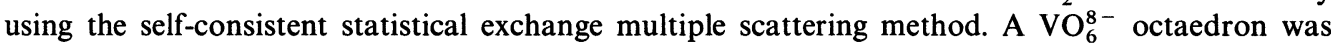
used to represent the tetragonal phase, and $a \mathrm{~V}_{2} \mathrm{O}_{10}^{12-}$ cluster with paired vanadium atoms was used for the monoclinic phase. Our results are in conflict with an explanation of the semiconducting gap in terms of simple distortion-induced band splitting.
\end{abstract}

Vanadium dioxide $\left(\mathrm{VO}_{2}\right)$ undergoes a transition from a high temperature metallic phase to a low temperature semiconducting phase at $340 \mathrm{~K}$ [1]. These two phases have different crystallographic structures. Metallic $\mathrm{VO}_{2}$ has a rutile tetragonal structure, each vanadium atom being located at the center of an oxygen octahedron (Fig. 1a). The low temperature phase is a monoclinic distortion of this rutile structure involving a pairing and off axis displacement of alternate vanadium ions along the rutile $c_{\mathrm{r}}$-axis (Fig. 1b). As a result, the crystal unit cell is doubled. Starting with the work of Adler and Brooks [2], there have been several theoretical descriptions in terms of band models [3, 4]. In these, the band-gap of semi-conducting $\mathrm{VO}_{2}$ originates completely from a modification of the band structure by the distortion. In order to investigate the validity of such descriptions we have made several cluster calculations of the electronic structure, both in the rutile and distorted

$\left(^{*}\right)$ Present address : Laboratory of Chemistry, University of Groningen, Groningen (Holland). configurations, by using the self-consistent statistical exchange multiple scattering method of Slater and Johnson [5]. This is an ab-initio calculation, which yields the splitting of the vanadium 3d-levels in the distorted structure. A complete detailed description of the calculations will be given elsewhere. We present here only the data and results relevant to the problem of the metal-insulator transition. We compare the band scheme inferred from our calculation to experimental data. A disagreement is found which is considered as evidence for the importance of intra-atomic correlations in inducing a band-gap.

Our calculations simulate a neutral cell of $\mathrm{VO}_{2}$ in the solid by surrounding each atomic species of the cluster with non-overlapping muffin tin spheres, and by enclosing the cluster with a so-called outersphere [5]. Three complete cluster calculations were performed, using a different geometry and/or a different number of atoms in each case. The quantities of main interest coming out of the calculation are the energies of the vanadium d-levels and the corresponding charge distributions. The clusters have been chosen 


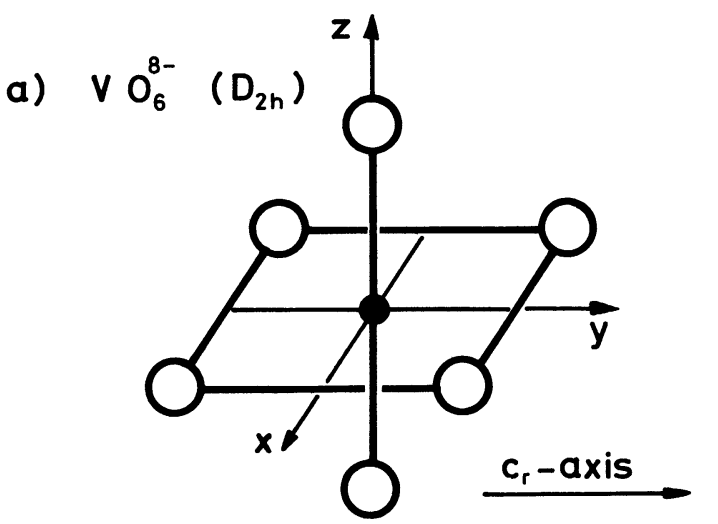

b) $\mathrm{V}_{2} \mathrm{O}_{10}^{12-}\left(\mathrm{C}_{2 \mathrm{~h}}\right)$

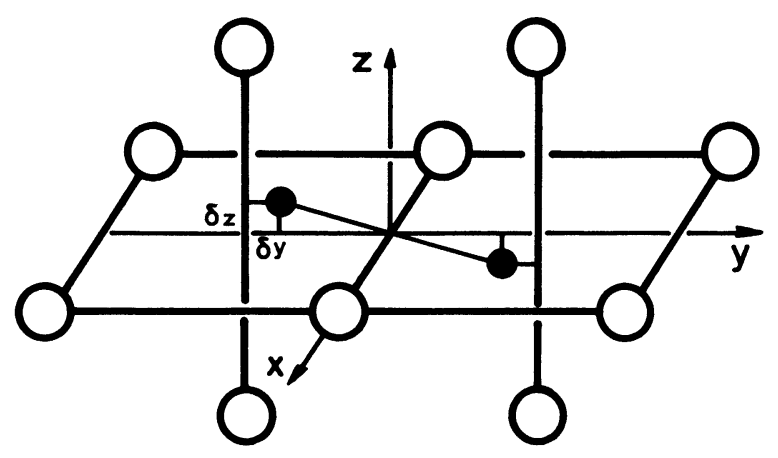

FIG. 1. - Atomic clusters used in the calculations : large spheres represent oxygen atoms and small spheres vanadium atoms. a) Single octahedron with atoms in the tetragonal phase positions.

b) Double octahedron with vanadium displácements $(0, \delta y, \delta z)$ corresponding to the monoclinic phase. to obtain a proper description of the vanadium dstates, which was evidenced by the fact that calculations showed only a small fraction (see Table I) of the d-state charge residing in the outer sphere region. This gives us confidence that the calculated energies of the d-levels describe correctly the mean positions of the corresponding energy bands in the actual solid.

To simulate the metallic phase we chose the basic $\mathrm{VO}_{6}^{8-}$ octahedron of the rutile structure (Fig. 1a). This configuration has $D_{2 \mathrm{~h}}$ symmetry. The energy of each d-level and the corresponding charge distribution are given in table I. The ordering of the d-levels is such that the $d_{x z}$ state is the last occupied one (containing one electron). The empty $d_{x^{2}-y^{2}}$ and $d_{y z}$ levels follow in order of increasing energy. We find that the orthorhombic splitting is small $(\simeq 0.05 \mathrm{eV})$, the lowest three $\mathrm{d}$-levels being almost degenerate. This group of levels gives rise in the crystal to the partially occupied lowest d-bands. Our calculations show that there is a sizable fraction $(\sim 6 \%)$ of the total charge contribution of these levels residing in the oxygen spheres. This tends to support $\pi$ bonding via the oxygens as the origin of the bandwidth [6]. Our results are consistent with the simplified band scheme discussed by Goodenough [6] : a $\pi^{*}$ band originates from the $d_{x z}$ and $d_{y z}$ levels, and it overlaps a $d_{\|}$band originating from the $d_{x^{2}-y^{2}}$ level (this $d_{\|}$band should be narrower, due to an unfavorable symmetry with respect to $\pi$ bonding).

In order for the system to become semiconducting, two distinguishable changes in the band structure are required : (i) a raising of the $\pi^{*}$ bands above the

TABLE I

Energy levels and charge distributions for the two clusters of figure 1. Energies are measured relative to the last filled level. The charge distributions for the different cluster regions are given, as well as the symmetry of the main components of the wavefunctions for the atomic spheres.

\begin{tabular}{|c|c|c|c|c|c|}
\hline \multirow{2}{*}{$\begin{array}{c}\text { Cluster } \\
-\end{array}$} & Energy $(\mathrm{eV})$ & $\begin{array}{l}\% \text { charge } \\
\text { in vanadium } \\
\text { spheres }\end{array}$ & $\begin{array}{c}\% \text { charge } \\
\text { in oxygen } \\
\text { spheres }\end{array}$ & $\begin{array}{c}\% \text { charge } \\
\text { in intersphere } \\
\text { region }\end{array}$ & $\begin{array}{c}\% \text { charge } \\
\text { in outersphere } \\
\text { region }\end{array}$ \\
\hline & - & - & - & - & 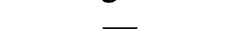 \\
\hline \multirow{6}{*}{$\begin{array}{l}\mathrm{VO}_{6}^{8-} \\
\left(D_{2 \mathrm{~h}}\right)\end{array}$} & 0 & $72 \quad(x z)$ & 6.0 & 22 & 0.09 \\
\hline & 0.04 & $72\left(x^{2}-y^{2}\right)$ & 6.0 & 22 & 0.10 \\
\hline & 0.06 & $73 \quad(y z)$ & 5.7 & 21 & 0.12 \\
\hline & 1.83 & $65 \quad\left(z^{2}\right)$ & 23 & 11 & 0.27 \\
\hline & 2.02 & $64 \quad(x y)$ & 24 & 11 & 0.28 \\
\hline & 3.75 & 0.45 & $19.4(\mathrm{~s}, \mathrm{p})$ & 72.7 & 7.4 \\
\hline \multirow{7}{*}{$\begin{array}{c}\mathrm{V}_{2} \mathrm{O}_{10}^{12-} \\
\left(C_{2 \mathrm{~h}}\right)\end{array}$} & 0 & $10.8\left(x^{2}-y^{2}\right)$ & $8.2(s, p)$ & 77 & 3.7 \\
\hline & 0.50 & $65\left(x^{2}-y^{2}\right)$ & 8.0 & 26 & 0.41 \\
\hline & 0.60 & $69 \quad(x z)$ & 2.1 & 29 & 0.48 \\
\hline & 0.61 & $72 \quad(x z)$ & 4.6 & 21 & 0.16 \\
\hline & 0.63 & $76\left(x^{2}-y^{2}\right)$ & 4.2 & 19 & 0.01 \\
\hline & 0.69 & $75 \quad(y z)$ & 6.8 & 18 & 0.03 \\
\hline & 0.71 & $72 \quad(y z)$ & 5.8 & 22 & 0.21 \\
\hline
\end{tabular}


Fermi energy, thus leaving the $d_{\|}$band half-filled, and (ii) a splitting of the $d_{\|}$band. It has been surmised by Goodenough [6] that the first requirement is mainly fulfilled through the shortening of one $\mathrm{V}-\mathrm{O}$ distance by the distortion, thus destabilizing the $\pi^{*}$ orbitals. This is achieved by a displacement of the vanadiums perpendicular to the rutile $c_{\mathrm{r}}$-axis. The splitting of the $d_{\|}$band can then result from formation of $\mathrm{V}-\mathrm{V}$ pairs, through alternate displacements along this axis [6]. Given these considerations, we have made several cluster calculations in order to investigate separately the changes in the energy levels produced by each component of the distortion.

In the low temperature phase of $\mathrm{VO}_{2}$ all atoms are displaced from their original rutile positions, and the basic octahedron loses all its symmetry elements [4]. We have approximated the oxygen positions by an octahedron of $D_{2 \mathrm{~h}}$ symmetry, according to the following procedure : (i) its center of symmetry is taken at the barycenter of the real oxygen positions; (ii) the symmetry axes are the original rutile axes (Fig. 1a); (iii) the coordinates of the two oxygens lying on the $z$ axis are obtained by averaging the true $z$ coordinates; (iiii) a similar averaging is done for the four oxygens lying in the $x y$ plane. The vanadium atom in semiconducting $\mathrm{VO}_{2}$ has coordinates $\delta x=0.016 \AA, \delta y=0.155 \AA, \delta z=0.113 \AA$ with respect to the center of the octahedron. As a first step, we have made a $\mathrm{VO}_{6}^{8-}$ cluster calculation with the vanadium atom at $(0,0, \delta z)$, in order to investigate the effect of the off $c_{\mathrm{r}}$-axis displacement $\left(C_{2 \mathrm{v}}\right.$ symmetry). This resulted in a reordering of the d-levels so that now $\mathrm{d}_{x^{2}-y^{2}}$ is the last filled level, the $\mathrm{d}_{x z}$ and $d_{y z}$ states being located $0.21 \mathrm{eV}$ and $0.26 \mathrm{eV}$ above in energy.

In order to include the effect of pairing one needs a larger cluster containing two vanadium atoms. We have taken a $\mathrm{V}_{2} \mathrm{O}_{10}^{12-}$ cluster with two adjoining octahedra along the $c_{\mathrm{r}}$-axis (Fig. $1 b$ ). The vanadium in one octahedron is at $(0, \delta y, \delta z)$ whereas the other is in the symmetric position with respect to the center of symmetry of the cluster (Fig. $1 b$ ). The small $\delta x$ component has been neglected so as to preserve $C_{2 \mathrm{~h}}$ symmetry. The last filled level now contains two electrons. Considering its charge distribution given in table $I$, we see that it is not simply a vanadium d-state but rather an admixture of vanadium $d$ wavefunctions (mainly $\mathrm{d}_{x^{2}-y^{2}}$ ) and oxygen $\mathrm{s}$ and $\mathrm{p}$ wavefunctions. This level corresponds to a covalent bond between the two vanadiums in the pair, obtained through admixture of wavefunctions on the oxygens [7]. It will give rise to the valence band in the semiconductor. Starting $0.5 \mathrm{eV}$ higher up in the energy we find a group of closely spaced d-levels corresponding essentially to vanadium d-states. These will give rise to the conduction band.

Comparing the above two calculations, namely distorted $\mathrm{VO}_{6}^{8-}\left(C_{2 \mathrm{v}}\right)$ and $\mathrm{V}_{2} \mathrm{O}_{10}^{12-}\left(C_{2 \mathrm{~h}}\right)$, we see that both components of the distortion have comparable effects in creating a band splitting, thus confirming Goodenough's qualitative description [6]. The question now arises as to whether the magnitude of the splitting can account for the band-gap. Our calculation gives a d-level splitting of $0.5 \mathrm{eV}$, and this would be the true band-gap only in the limit of zero bandwidth. Optical measurements $[8,9]$ in the metallic phase indicate a bandwidth of order one to two electronvolts [10], in agreement with the band calculations of Caruthers et al. [11]. In Goodenough's description [6] this corresponds to the $\pi^{*}$ bandwidth. Since we found a comparable admixture of oxygen wavefunctions with the vanadium d-states in both structures, we expect a comparable bandwidth for the band originating from the empty d-levels. Therefore one would expect this band and the valence band to either overlap, or at most be separated by a band-gap appreciably smaller than the calculated level separation of $0.5 \mathrm{eV}$. Experimentally, an activation energy $E_{\sigma}=0.45 \pm 0.05 \mathrm{eV}$ for the conductivity above room temperature has been reported for good quality samples by several authors [12-14], and recent thermoelectric power measurements $\left({ }^{*}\right)$ show that this is effectively due to excitation of carriers, as opposed to an activated mobility. From these results one deduces an energy gap for carrier excitation lying between $2 E_{\sigma}=0.9 \mathrm{eV}$ and $0.7 \mathrm{eV}$, depending on assumptions of the temperature dependence of the gap [15]. We thus find a definite disagreement with the much smaller value inferred from the cluster calculation by taking into account bandwidths.

It therefore appears necessary to consider the intra-atomic electron repulsion as responsible for opening the gap. This is corroborated by : (i) estimations of the intra-atomic correlation energy $U$ [16] (*) which yield values of a few electron-volts; (ii) the observation of localized moments on vanadium sites in the insulating phase of $\mathrm{V}_{1-x} \mathrm{Cr}_{x} \mathrm{O}_{2}$ alloys [17], for which the pairing is partially suppressed.

We wish to thank Professor J. W. D. Connolly for a copy of his MST computer program.

(*) BuChy et al. Private communication.

(*) Sommers, C. and DE Groot, R., Unpublished.

\section{References}

[1] Morin, F. J., Phys. Rev. Lett. 3 (1959) 34.

[2] Adler, D. and Brooks, H., Phys. Rev. 155 (1967) 826.

[3] Hearn, C. J., J. Phys. C 5 (1972) 1317.

[4] Caruthers, E. and Kleinman, L., Phys. Rev. B 7 (1973) 3760.

'[5] Slater, J. C. and Johnson, K. H., Phys. Rev. B 5 (1972) 844.
[6] Goodenough, J. B., J. Sol. Stat. Chem. 3 (1971) 490.

[7] In the rutile $\mathrm{VO}_{6}^{8-}\left(D_{2 \mathrm{~h}}\right)$ cluster calculation, we find an oxygen s and $p$ level lying not far above the vanadium d-levels (Table I). Covalent bonding presumably occurs by admixture with this state. Note the large amount of intersphere 
charge both for this state and for the lowest state in the $\mathrm{V}_{2} \mathrm{O}_{10}^{12-}\left(C_{2 \mathrm{~h}}\right)$ cluster.

[8] Verleur, H. W., Barker, A. S., Jr. and Berglund, C. N. Phys. Rev. 172 (1968) 788.

[9] Fan, J. C. C., Techn. Rep. No HP-28, Division of Engineering and Applied Physics, Harvard University, Cambridge, Massachussetts.

[10] Paul, W., Mat. Res. Bull. 5 (1970) 691.

[11] Caruthers, E., Kleinman, L. and Zhang, H. I., Phys. Rev. B 7 (1973) 3753.
[12] Kabashima, Goto, T., Nishimura, K. and Kawakubo, T., J. Phys. Soc. Japan 32 (1972) 158.

[13] Ladd, L. A. et Paul, W., Solid State Commun. 7 (1969) 425.

[14] Borisov, B. S., Koretskaya, S. T., Mokerov, V. G., RaKov, A. V. and Solov'ev, S. G., Sov. Phys. Solid State 12 (1971) 1763.

[15] Zylbersztejn, A. and Mott, N. F., Submitted to Phys. Rev. B. [16] Hyland, G. J., Phil. Mag. 20 (1969) 837.

[17] Pouget, J. P., Launois, H., Rice, T. M., Dernier, P., Gossard, A., Villeneuve, G. and Hagenmuller, P., Phys. Rev. B 10 (1974) 1801. 